\title{
Liquid-Liquid Extraction and Chromatography Process Routes for the Purification of Lithium
}

\author{
Axel Schmidt ${ }^{1}$, Fabian Mestmäcker ${ }^{1}$, Lisa Brückner ${ }^{2}$, Tobias Elwert $^{2}$ \\ and Jochen Strube ${ }^{1 *}$ \\ ${ }^{1}$ Institute for Separation and Process Technology, \\ Faculty of Mathematics/Computer Science and Mechanical Engineering, \\ Clausthal University of Technology, 38678 Clausthal-Zellerfeld, Germany \\ ${ }^{2}$ Institute of Mineral and Waste Processing, Waste Disposal and Geomechanics, \\ Faculty of Energy and Management, \\ Clausthal University of Technology, 38678 Clausthal-Zellerfeld, Germany
}

\begin{abstract}
Keywords: Lithium, separation, recycling, liquid-liquid extractions, chromatography, electromobility, LLE, processing lithium
\end{abstract}

\begin{abstract}
Since several years, the lithium market is characterized by high growth rates especially due to the increasing demand for lithium-ion batteries. Therefore, the primary production is currently expanded and there is a growing interest in recycling. However, because of the chemical properties of lithium, many production processes lack efficient processes for the separation, concentration and purification of lithium. This article reviews the current use of liquid-liquid extraction (LLE) and chromatography in lithium production as well as research.

Currently, the industrial application of LLE and chromatography in lithium purification is limited to the extraction of impurities and co-products. Extraction of lithium is only used as concentration step in few processes before lithium precipitation. In research and development, a wide variety of extractants and resins is investigated. In LLE, chelating extractants like crown ethers and calixarene and synergistic systems show the greatest potential. In the chromatographic separation the main focus of research lies upon cation exchange media, especially media with sulfonated ligands. However, most research is still in early development. Therefore, extensive research is needed to enable the industrial use of optimized LLE and chromatography processes in lithium production.
\end{abstract}

\section{Introduction}

Since several years, lithium production has shown high growth rates mainly caused by an increasing demand for lithium-ion batteries (LIB) (1). Due to the expected breakthrough of electromobility, this development will presumably continue at an even higher pace. Consequently, primary lithium production as well as lithium recycling has come to the fore in recent years. Whereas for the primary production industrially established processes are available, recycling is still at the beginning and focuses on LIBs (2).

As an alkali metal, lithium is highly reactive (electrode potential: $-3.045 \mathrm{~V}$ ), possesses relatively small effective ion radii ( $\mathrm{r}=0.73-1.06 \AA$ depending on the coordination number) and low ionic charge $(+1)$, and most of its salts are highly soluble (3). Hence, the separation of lithium from other metals is a challenging task. For example, the diagonal relationship of lithium with magnesium, an element of similar ionic radius, results in chemical resemblances and causes low lithium yields in some process routes $(4,5)$. Therefore, the development of highly selective purification operations like liquid-liquid extraction (LLE) and chromatography are of high interest. However, currently these technologies play only a minor role in lithium processing due to its chemical properties $(2,4)$. The aim of this article is to give an overview of current lithium production processes and the possible application of LLE and chromatography for the purification and enrichment of lithium. Therefore, the first part describes briefly the primary production routes for lithium as well as recycling processes under development and highlights potential applications of LLE and 
chromatography. The second part reviews critically LLE and chromatography systems for lithium extraction and purification. In the last part, future prospects and research needs are deduced.

\section{Lithium Production}

Currently, lithium is almost exclusively produced from primary resources, namely spodumene ( $\left.\mathrm{LiAlSi}_{2} \mathrm{O}_{6}\right)$ containing pegmatites and lithium containing brines. The contribution of recycling is negligible, but expected to increase significantly in the upcoming decades, especially from spent LIBs (1). In the following, the main primary production routes and recycling processes are briefly described.

\subsection{Primary production}

Global mine production in 2017 was about 43,000 mt lithium. Lithium carbonate is mainly produced from continental brines, especially in Chile and Argentina followed by China. The main producer of spodumene concentrates is Australia. In the last decades, spodumene concentrates have mainly been used directly in the ceramic industry. However, due to a strong increase in demand and rising lithium prices, production of lithium carbonate from spodumene gains in importance (1).

\subsubsection{Lithium carbonate production from continental brines}

Natural brines with high lithium chloride content, which are the result of natural leaching evaporation processes, are nowadays the most important source for industrial production of lithium products. The highest lithium concentrations can be found in the high-altitude salt lakes (salars) in Bolivia, Argentina, Chile, and China (4). Typical analyses of Li-containing brines are given in Table 1.

Table 1: Selected typical lithium-bearing brine compositions. All figures in wt\%. Other elements and compounds may also be present (6).

\begin{tabular}{ccccccc}
\hline & $\begin{array}{c}\text { Clayton } \\
\text { Valley, } \\
\text { USA }\end{array}$ & $\begin{array}{c}\text { Salar de } \\
\text { Atacama, } \\
\text { Chile }\end{array}$ & $\begin{array}{c}\text { Salar de } \\
\text { Hombre } \\
\text { Muerto, } \\
\text { Argentina }\end{array}$ & $\begin{array}{c}\text { Salar de } \\
\text { Rincon, } \\
\text { Argentina }\end{array}$ & $\begin{array}{c}\text { Zhabuye } \\
\text { Salt Lake, } \\
\text { China }\end{array}$ & $\begin{array}{c}\text { Qaidam } \\
\text { Basin Salt } \\
\text { Lakes, } \\
\text { China }\end{array}$ \\
\hline $\mathrm{Li}$ & $0.02-0.04$ & $0.11-0.31$ & $0.05-0.06$ & 0.03 & $0.05-0.10$ & $0.01-0.03$ \\
$\mathrm{~K}$ & $0.53-1.00$ & $1.80-2.97$ & $0.52-0.62$ & $0.62-0.66$ & $2.64-3.83$ & $0.60-0.66$ \\
$\mathrm{Mg}$ & $0.03-0.06$ & $0.82-1.53$ & $0.05-0.09$ & $0.28-0.30$ & $0-0.001$ & $0.47-3.51$ \\
$\mathrm{Ca}$ & $0.02-0.05$ & $0.02-0.04$ & $0.05-0.099$ & $0.04-0.06$ & $0-0.001$ & $0.02-0.42$ \\
$\mathrm{~B}$ & $0.00-0.01$ & $0.06-0.07$ & $0.02-0.04$ & 0.04 & $0.29-1.46$ & $0.03-0.05$ \\
$\mathrm{Na}$ & $6.20-7.50$ & $1.03-9.10$ & $9.79-10.30$ & $9.46-9.79$ & $10.66-10.81$ & $6.20-6.84$ \\
$\mathrm{Cl}$ & $10.10-$ & $2.03-19.85$ & $15.80-16.80$ & 15.80 & $12.16-12.31$ & $9.20-20.42$ \\
\hline
\end{tabular}

As lithium concentrations in brines are relatively low, the first processing task is to concentrate the brines. The most efficient way of concentration is by solar evaporation in large pond systems. In principal, this process is applicable to many lithium-containing salars. However, in reality the process must be adapted very thoroughly to each individual salar, as lithium concentration, $\mathrm{Mg} / \mathrm{Li}$ ratio, impurity profile, evaporation rate, rainfall, and ambient temperature are different for each salar. Each of these factors influences the process in a positive (e.g., high lithium concentration or high evaporation rate) or negative (e.g., high $\mathrm{Mg} / \mathrm{Li}$ ratio, leading to the undesired crystallization of $\mathrm{LiCl} \cdot \mathrm{MgCl}_{2} \cdot 6 \mathrm{H}_{2} \mathrm{O}$ ) way and in consequence impacts the overall economics of lithium extraction (4). 


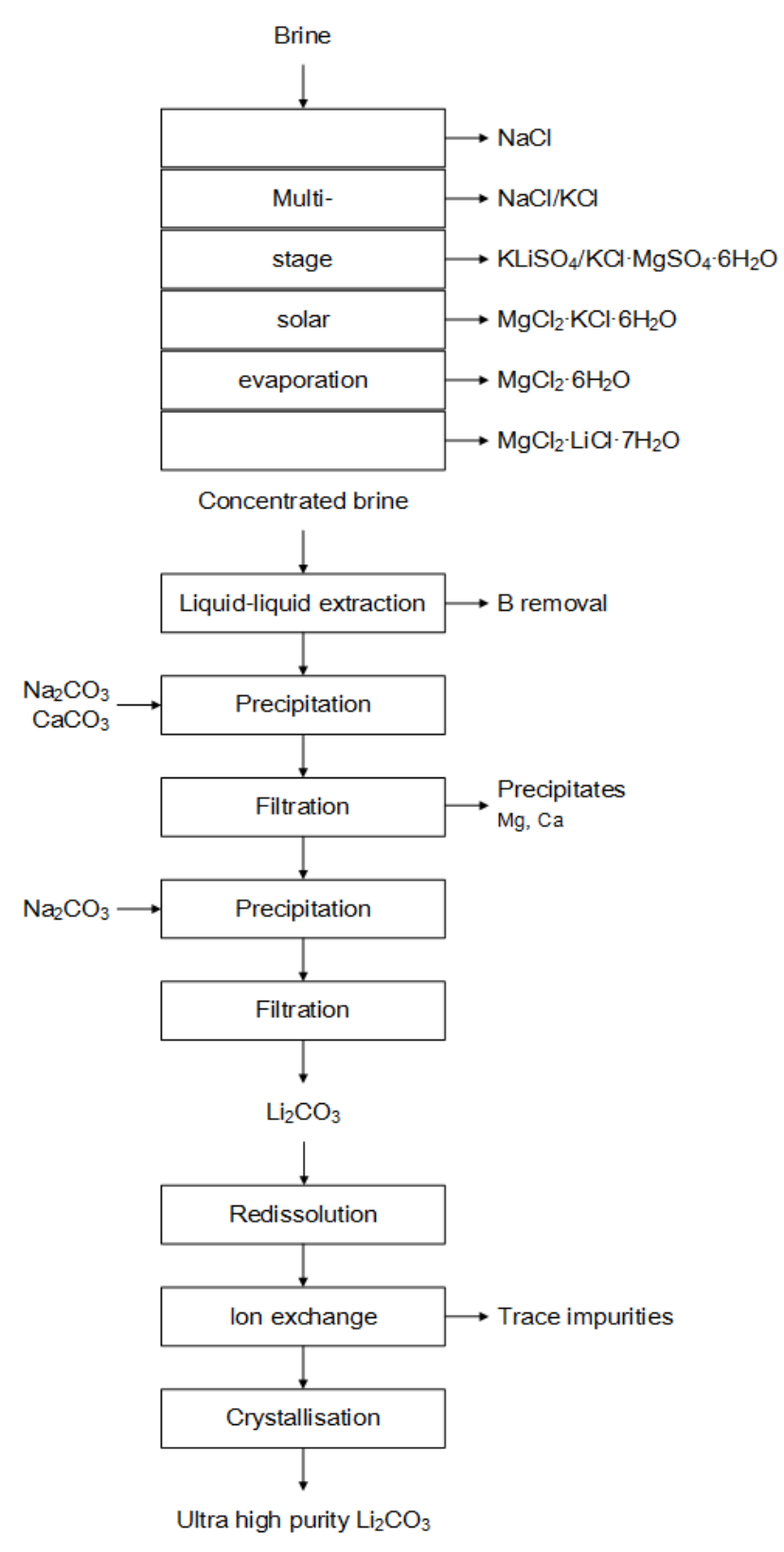

In the following Figure 1, the Atacama process is presented as one example. The brines are pumped from a depth of some tens of meters to a series of solar ponds. The brine is sent from one pond to another while the concentration of the brine increases continuously. Depending on the concentration, certain salts crystallize due to oversaturation and are harvested as byproducts. During the evaporation process the lithium concentration increases from ca. $2000 \mathrm{ppm}$ to about 60,000 ppm. Depending on the concentration and composition of the brine and the evaporation efficiency, it takes between 12 and 18 months to obtain the final lithium concentration (4).

The concentrated brine first undergoes additional purification steps, especially to remove boron, magnesium, and calcium. Boron is separated by liquid-liquid extraction (LLE), also called solvent extraction, with a mixture of alcohol-kerosene. A small amount of soda ash is added to the brine to precipitate magnesium carbonate. The addition of lime removes magnesium and sulfate residues. The purified lithium chloride solution is then treated with soda ash to form lithium carbonate. The precipitation is carried out near the boiling point due to the decreasing solubility of lithium carbonate with increasing temperature (solubility: 13.3 $\mathrm{g} / \mathrm{L}$ at $20^{\circ} \mathrm{C} ; 7.2 \mathrm{~g} / \mathrm{L}$ at $\left.100^{\circ} \mathrm{C}\right)$. After washing, the final product is filtered and dried (4).

To produce high grade lithium products of $>99.9 \%$ purity, lithium carbonate (ca. $99.5 \%$ purity) needs to be redissolved into solution from brines (adapted from (7)).

as $\mathrm{LiHCO}_{3}$. Further purification by ion exchange will remove more impurities caught in the lithium carbonate structure rendering high purity liquor for final lithium carbonate ( $>99.9 \%$ purity) recovery (7).

\subsubsection{Lithium production from spodumene concentrates}

Spodumene concentrates are typically produced by flotation and contain $4.8-7.5 \% \mathrm{Li}_{2} \mathrm{O}$. A variety of processes for the production of lithium products from spodumene are described in literature, but only the sulfuric acid route is of industrial importance for economic reasons and described in the following (see Figure 2) (4).

Prior to digestion, spodumene requires pretreatment (decrepitation) to convert $\alpha$-spodumene to $\beta$ spodumene due to the high chemical stability of the $\alpha$-form. Decrepitation is carried out in rotary kilns at $1000-1100^{\circ} \mathrm{C}$. In the sulfuric acid digestion, lithium is converted into soluble lithium sulfate at about $250^{\circ} \mathrm{C}$. Then, the lithium sulfate is leached with hot water. After leaching, aluminum silicate residues are removed by filtration and the filtrate is treated with lime and soda to precipitate alkaline earth metals and iron. After repeated filtration, further removal of impurities is 
conducted by ion exchange. The purified lithium sulfate solution is concentrated either by evaporation or ion exchange up to $200-250 \mathrm{~g} / \mathrm{L}$ of lithium sulfate. The precipitation of lithium carbonate by concentrated sodium carbonate solution is carried out near the boiling point. Lithium carbonate is removed by filtration or centrifugation and washed with hot water to remove the adhering mother liquor. Alternatively, feasibility studies with an electrodialysis module have been performed to produce a $\mathrm{LiOH}$ solution from purified $\mathrm{Li}_{2} \mathrm{SO}_{4}$ solution obtained after impurities are removed by precipitation and ion exchange. The $\mathrm{LiOH}$ solution generated is then heated to concentrate lithium values and a crystallization stage is finally conducted to yield $\mathrm{LiOH} \cdot \mathrm{H}_{2} \mathrm{O}$. $\mathrm{High}$ purity $\mathrm{Li}_{2} \mathrm{CO}_{3}$ and $\mathrm{LiOH} \cdot \mathrm{H}_{2} \mathrm{O}$ of $>99.9 \%$ grade can be produced from these processes $(4,7)$.

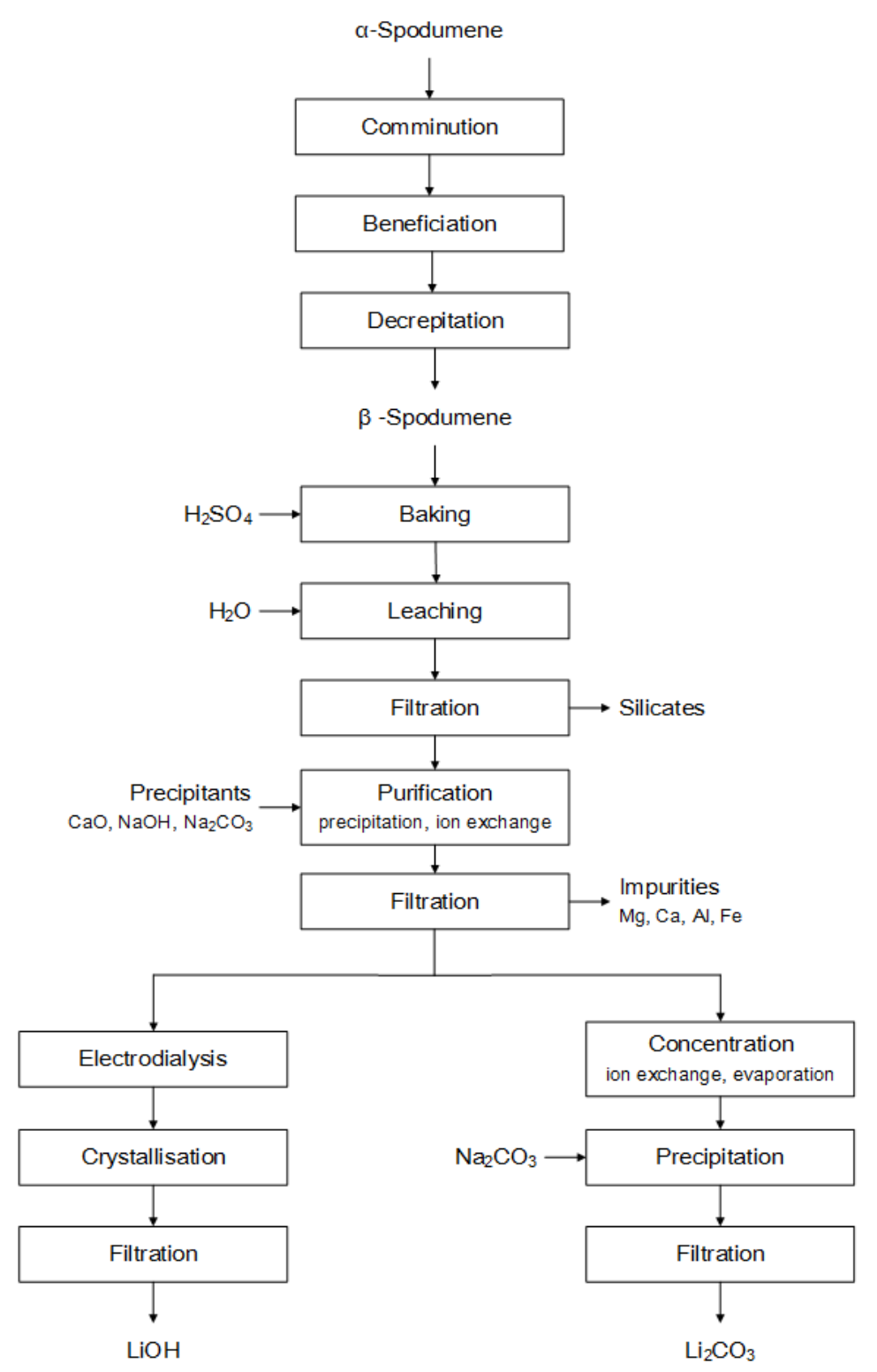

Figure 2: Flow sheet for lithium production from spodumene concentrates (adapted from $(4,7)$ ).

\subsection{Recycling}

Interest in recycling of lithium is relatively new and focuses on LIBs (1). However, lithium has not been the main driver of LIB recycling in recent years due to its comparatively low price, difficult recoverability, and its low concentration. The recycling of LIBs was motivated by the mitigation of risks (fire hazards, toxic components) and the recovery of high-value and easy to extract transition metals such as cobalt, nickel, and copper. However, due to the fast growing lithium demand and increasing prices, lithium recovery currently attracts more attention (2). 
In the last 15 years, two general approaches have been pursued in the industrial-driven recycling of LIBs. In the first approach (see Figure 3), the battery cells enter a pyrometallurgical treatment with minimum or without mechanical pretreatment followed by further treatment of the process outputs (alloy, slag, flue dust) mainly by hydrometallurgical processes to recover the individual metals. These processes have a strong focus on the recovery of cobalt, nickel, and copper, which are collected in the alloy phase, with an optional recovery of lithium from the slag or flue dust phase. Other ignoble metals, e.g., aluminum, graphite, and organics are utilized as reductants and heat source, but are not recovered. In the second approach (see Figure 4), the processes are typically a combination of mechanical treatment of the cells and a specific hydrometallurgical treatment of the active electrode materials $(2,8)$. In the next two sections, both approaches are briefly described. For further information about LIB recycling, see (2).

\subsubsection{Recovery of lithium from slags}

The most prominent example of the first approach is the Umicore Battery Recycling Process. The process is based on an $\mathrm{Al}_{2} \mathrm{O}_{3}-\mathrm{CaO}-\mathrm{Li}_{2} \mathrm{O}-\mathrm{MgO}-\mathrm{SiO}_{2}$ slag system, with varying concentrations of $\mathrm{MnO}$. Typical $\mathrm{Li}_{2} \mathrm{O}$ contents are in the range of $8-12 \%(9,10)$. Due to similar components as in spodumene, lithium can be recovered by a similar process (see Figure 3), which was published by Elwert et al. (5). Advantages of the slags in comparison to spodumene concentrates are the significantly higher $\mathrm{Li}_{2} \mathrm{O}$ contents as well as their lower chemical stability.

In a first step, the quenched slag is grinded. After removing previously enclosed alloy drops by magnetic separation, the slag is leached with diluted sulfuric acid. After filtration of the solid residue, mainly gypsum and amorphous silicates, impurities are precipitated stepwise with lime to remove aluminum, manganese, etc. as hydroxides. In a last purification step, remaining calcium and magnesium are removed by adding sodium carbonate. After filtration, the lithium concentration of the solution is increased by evaporation and the lithium is precipitated as lithium carbonate by adding $\mathrm{Na}_{2} \mathrm{CO}_{3}$ near the boiling point. Lithium carbonate purities of ca. $98 \%$ and lithium yields of $65 \%$ are reported. It is assumed that the high lithium losses are partially caused by co-precipitation due to the diagonal relationship of lithium with magnesium, an element of similar ionic radius, which results in chemical resemblances between the two elements (5).

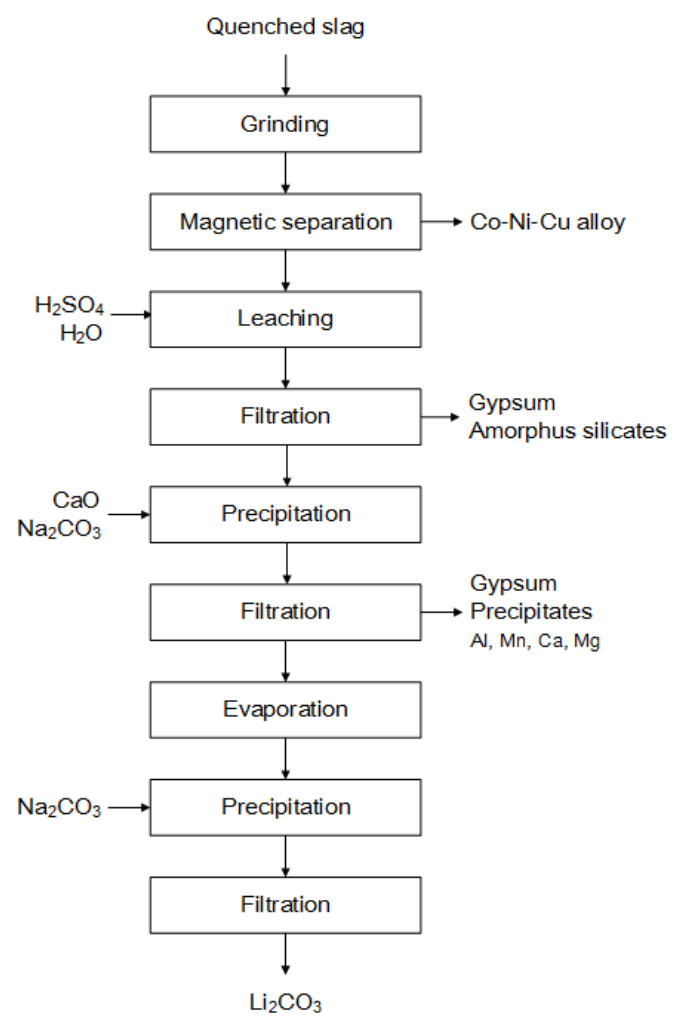

Figure 3: Flow sheet for the hydrometallurgical production of lithium carbonate from slags of the Umicore Battery Recycling Process (adapted from (5)). 


\subsubsection{Recovery of lithium from active electrode materials}

Processes following the second approach, typically concentrate the active electrode materials in one fraction by mechanical treatment including comminution, classifying, magnetic separation, etc. (11). The composition of these fractions can differ considerably depending on battery input, process design and efficiency. Besides graphite and lithium transition metal compounds such as $\mathrm{LiMO}_{2}$ with $\mathrm{M}=\mathrm{Co}, \mathrm{Ni}, \mathrm{Mn}, \mathrm{Al}, \mathrm{LiFePO}_{4}, \mathrm{LiMn}_{2} \mathrm{O}_{4}$, and $\mathrm{Li}_{4} \mathrm{Ti}_{5} \mathrm{O}_{12}$, electrolyte residues ( $\mathrm{LiPF}_{6}$ and solvents), binder residues and metallic impurities $(\mathrm{Al}, \mathrm{Cu}, \mathrm{Fe})$ might be present.

The concentrates are treated in most cases by hydrometallurgy to recover the metals of interest (11). Reviewing the available literature and patents, the majority of processes under development follow a similar approach, which Figure 4 shows schematically.

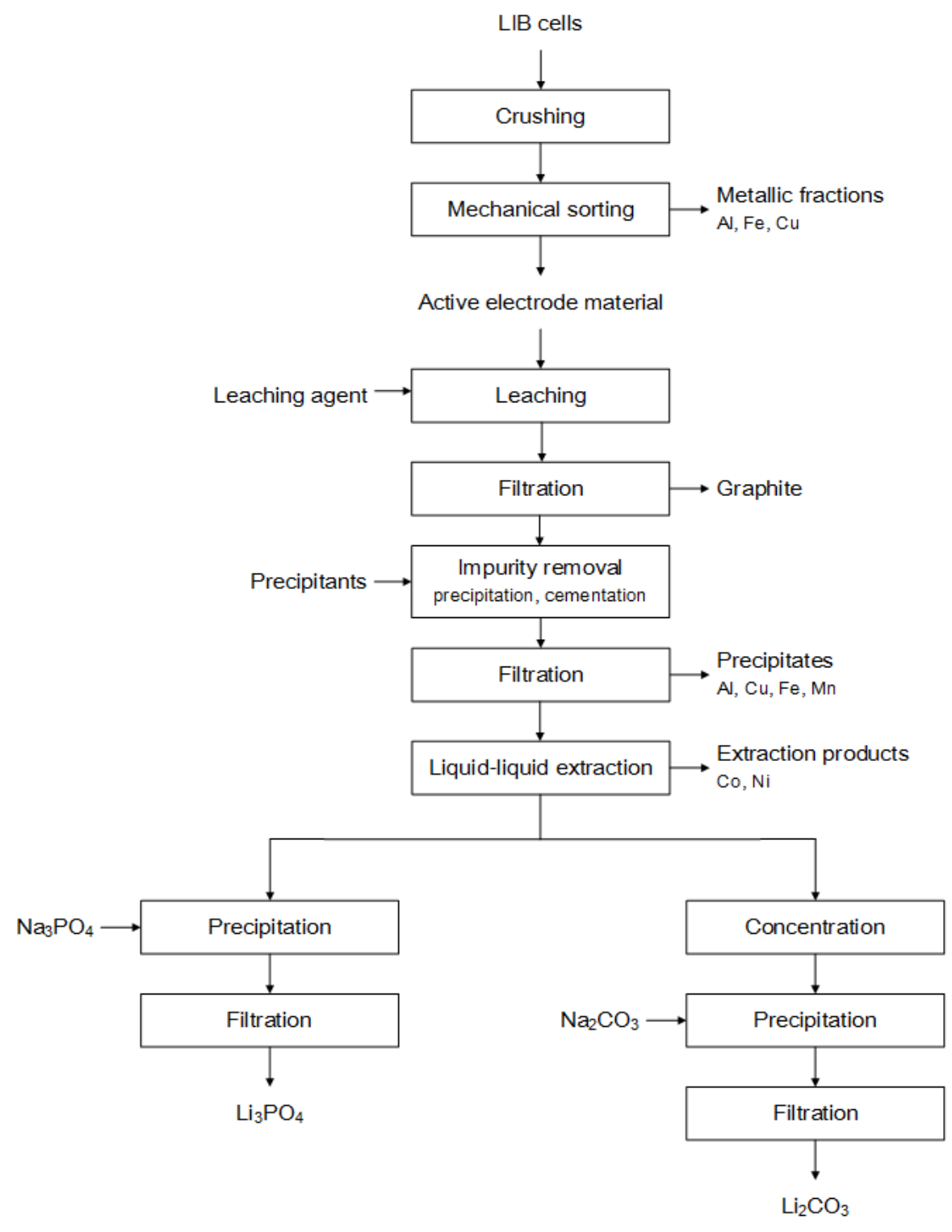

Figure 4: Flow sheet for the hydrometallurgical recovery of lithium from active electrode materials.

The processes start with leaching of the metals, which results in a pregnant leach solution and a graphite residue. As lixiviants, mineral acids such as sulfuric acid are most commonly used. In few cases, especially for $\mathrm{LiFePO}_{4}$, also alkaline treatment can be considered. After leaching, minor constituents and elements of lower value are often removed by precipitation (e.g., Al, Fe, Ti, Mn) or cementation (e.g., $\mathrm{Cu}$ ). Metals of high value and present in sufficient concentration might be separated and purified by LLE to produce high grade compounds suitable for battery production. From the remaining lithium containing solution, lithium is precipitated as phosphate or carbonate, if necessary after concentration by evaporation or membrane processes. 


\subsection{Possible applications for LLE and chromatography in lithium production}

Looking at the processes described above, three major problems occur in most processes. First, in nearly all processes lithium needs to be concentrated to enable an efficient precipitation as lithium carbonate. This applies especially to brines (see Table 1) where lithium concentrations are often in the X00 ppm range.

Second, during the removal of impurities lithium losses occur. This is especially true for magnesium containing raw materials due to the formation of mixed $\mathrm{Li}-\mathrm{Mg}$-compounds (see brines and lithium slags).

Third, despite impurity removal prior to lithium precipitation, the obtained lithium carbonate often contains levels of impurities (mainly other alkali and alkaline earth metals), which impede a direct use in high-tech applications such as LIBs. Therefore, a further purification process is required based on hybrid-separation technology and process design as a tool for process intensification (1214).

Consequently, highly selective operations for the extraction purification and concentration of lithium are of high interest in order to shorten process chains, to enable process intensification, to achieve better product qualities and to lower production of low value by-products (15).

\section{Liquid-Liquid Extraction}

Liquid-liquid extraction (LLE), often referred to as solvent extraction, is a common process for the selective extraction, separation, purification and concentration of a wide range of metals. LLE uses various organic extraction agents or extractants, which are dissolved in an organic carrier phase, usually called diluent. This diluent phase is brought into contact with an aqueous, usually acidic feed phase, which contains the dissolved metal ion or ion complex. Hence, the term liquid-liquid extraction implies the use of two non-miscible phases. The target metal ion depleted phase after extraction is defined as raffinate. The product enriched phase is called the extract (16). For a complete process usually two additional steps are implemented (17). During the scrubbing stage, the extract phase is depleted from side components to isolate the target metal ion. This side component enriched stream can then be redirected into the extraction stage. Afterwards, the target metal ion is stripped from the organic phase into an aqueous stripping stream to obtain a pure product and the extractant phase, that can be redirected to the initial extraction stage, either directly or after passing a regeneration stage (see Figure 5).

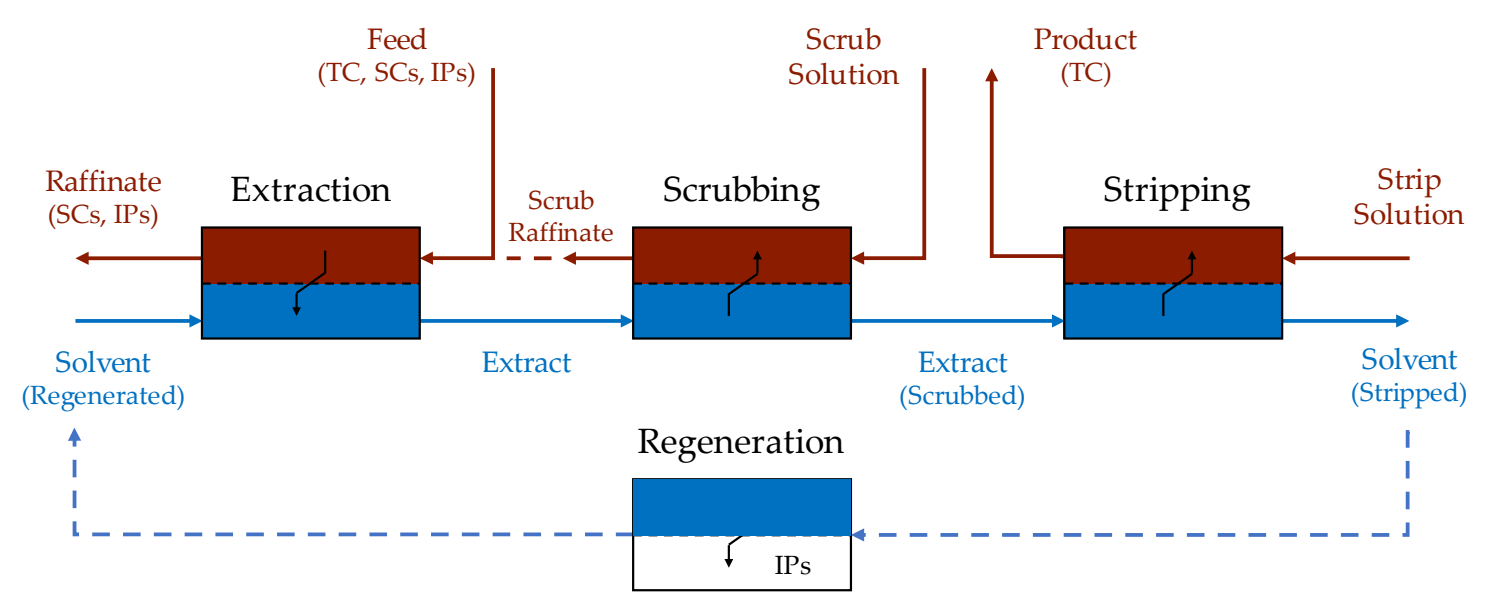

\footnotetext{
Aqueous Phase

TC: Target Component Organic Phase SCs: Side Components IPs: Impurities
}

Figure 5: Typical LLE flowsheet. 


\subsection{Liquid-Liquid Extraction Basics}

The fundamental basis of LLE is the $\mathrm{n}$ uneven distribution of the target component between the organic and the aqueous phase, which leads to the actual separation. The metals in the aqueous solution are present as charged species and are therefore not soluble in the organic non-polar solvent. However, adding complexing agents to the solution allows the formation of uncharged metal-extractant-species. These hydrophobic complexes can then be extracted into the organic phase, resulting in the desired uneven distribution of the metals and ultimately allowing the separation of the metals. LLE can also be used when the selectivity of the extractant for one metal is only slightly higher than for the others. The complete separation is then achieved by multi-stage extraction in countercurrent mode $(18,19)$. Due to the countercurrent flow, it is possible to selectively extract the individual metal ions, e.g. lithium ions, initially present as a mixture from the solution $(20,21)$.

There are three fundamental parameters that characterize LLE. The distribution coefficient D describes the ratio of the concentration of the target component in the organic solvent phase and the concentration in the aqueous phase.

$$
\mathrm{D}=\frac{\mathrm{c}_{\mathrm{org}}}{\mathrm{c}_{\mathrm{aq}}}
$$

The higher the distribution coefficient of an extraction, the lower the number of steps to achieve complete recovery of the target element into the organic phase. The efficiency is typically abbreviated to $\mathrm{E}$ and is linked to the distribution coefficient $\mathrm{D}$ and the solvent ratio $\mathrm{V}$ via the following relationship:

$$
\mathrm{E}=100 \times \frac{\mathrm{D} v}{1+\mathrm{Dv}_{\mathrm{v}}}
$$

The selectivity $\mathrm{S}$ of an extraction is defined by the effectiveness with which the target element $\mathrm{i}$ can be separated from a secondary component $\mathrm{j}$. The selectivity thus corresponds to the ratio of the distribution coefficient of the target component and the distribution coefficient of the secondary component.

$$
\mathrm{S}=\frac{\mathrm{D}_{\mathrm{i}}}{\mathrm{D}_{\mathrm{j}}}
$$

\subsection{Extractants and Mechanisms}

\subsubsection{Chelating Extractants}

The structure of crown ethers and their derivatives allows for forming multidentate complexes and is particularly suitable for the selective extraction of alkali metals and has been used several times for the separation of lithium (22-29). An overview of a 12-crown-4-ether and four derivatives is shown in Figure 6. 

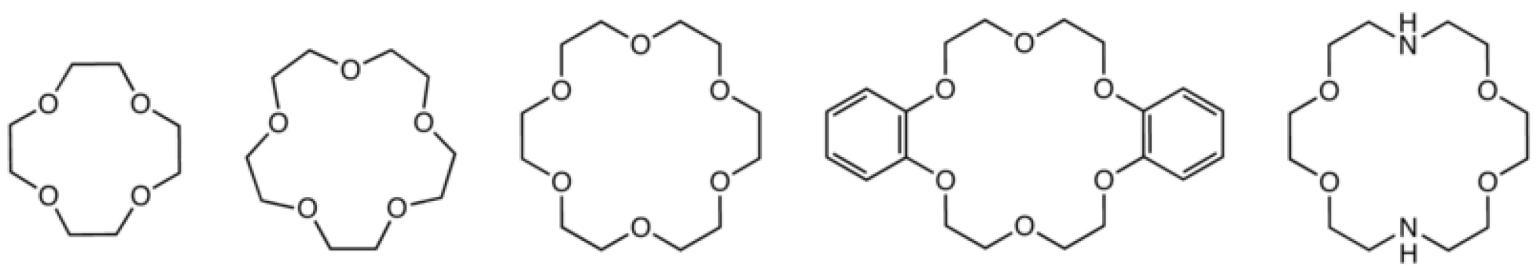

Figure 6: 12-crown-4-ether (left) and different derivatives to enhance selectivity.

The complexing mechanism due to the multidentate structure of the crown ethers is based on the Pearson principle of hard/soft/acid base (HSAB). It states that soft acids prefer to bind to soft bases and that hard acids therefore prefer to form bonds with hard bases. The uncombined electron pairs of oxygen atoms in the crown ethers serve as donor atoms according to the principle and may form the chemical bonds in a complex structure with the lithium or other alkali metal ions, which represent the correspondingly strong acid. According to Bartsch, the sequence in which the alkali metals form complexes with the crown ethers depend on the fit principle. As a result, the cavity of the crown ether and the ion radius of the alkali metal ion determine the complex stability $(24,25$, $30)$.

Calixarene are classified as metacyclophanes and are synthesized by a condensation reaction of palkylphenol with formaldehyde. Similar to the complexation reaction of crown ethers, calixarenes can form specific bonds with alkali metals.

The suitability of calixarenes for the extraction of lithium and other alkali metals has been investigated several times (31-36). A model of the extraction of a lithium ion into the calyx structure of a calixarene can be seen in Fehler! Verweisquelle konnte nicht gefunden werden..

Since crown ethers and calixarene are comparatively expensive extractants, their use is nowadays limited to analytical areas. Their great potential for the extraction of lithium lies in their very high selectivity for specific monovalent ions against multivalent and other monovalent ions. Since the costs for crown ethers and calixarene will probably continue to exceed those of typical commercial extractants in the future, their area of application can be assumed to be further downstream in the process chain, where only smaller volumes are to be processed, but separation will become more difficult. In particular, research must be carried out to develop optimum separation sequences in order to keep the amount of extractants required as low as possible in advance, and to deal with robust and efficient recovery and regeneration steps in order to ensure the longest possible lifetime and use of the chelating extractants.

\subsubsection{Acidic Extractants}

In the field of metal recovery from LIBs, organophosphoric acid derivatives such as P204, P507 or Cyanex 272 are usually used in LLE.
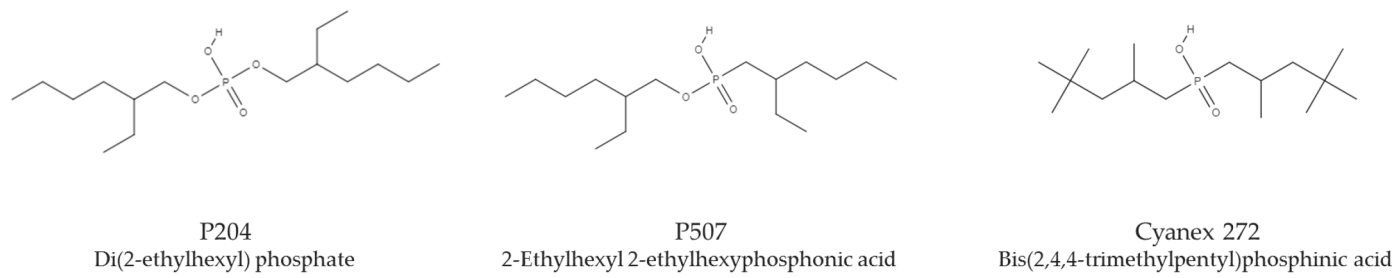

Figure 7: Most commonly used commercial acidic extractants.

Hano et al. investigated the extraction of alkali and alkaline earth metals with P204 and MEHPA (2ethylhexylphosphoric acid 2-ethylhexyl ester) as extractants. They found that these extractants show a high selectivity for lithium in presence of other monovalent cations. Furthermore, the affinity of divalent ions is much higher in comparison to lithium and they suggested the separation of lithium and the divalent ions via stripping stages. Additionally experiments were performed with tri-nbutylphosphate (TBP) as solvating co-extractant, which showed a synergistic effect for the extraction efficiency as well as recovery of lithium (37). Swain et al. investigated the separation of cobalt and lithium with Cyanex 272 and could not show a strong extraction capacity of Cyanex 272 
for the extraction of lithium in the acidic regions of the acidic sulfate solution investigated. They support their finding by reciting the literature, where low extraction capacity of lithium by commercial acidic extractants such as Cyanex 272, P204, P507 was reported during solvent extraction of other base metals in the acidic $\mathrm{pH}$ range of the aqueous phase $(29,38-43)$.

The extraction mechanism involves the exchange of hydrogen ions $\mathrm{H}^{+}$for the selected metal cation $\mathrm{M}^{\mathrm{n}+}$ (with $\mathrm{n}$ as the number of exchanged protons), which leads to the following general equation, where the bar over top of a molecule indicates the organic phase (44):

$$
\mathrm{M}^{\mathrm{n}+}+\mathrm{n} \overline{\mathrm{HL}} \rightleftharpoons \overline{\mathrm{ML}_{\mathrm{n}}}+\mathrm{nH}^{+}
$$

Using the dimeric form of the extractant HL results in the modified version of eq. (3.4):

$$
\mathrm{M}^{\mathrm{n}+}+\frac{\mathrm{n}}{2}(\overline{\mathrm{HL}})_{2} \rightleftharpoons \overline{\mathrm{ML}_{\mathrm{n}}}+\mathrm{nH}^{+}
$$

Overall, due to the low affinity of lithium to acidic extractants, only few studies have been published. Since the possibilities for extracting lithium with these extraction agents are limited, these acidic extraction agents cannot be used for the extraction of lithium. However, to separate side components from mediums like LIB leach solutions, there are studies in literature that use these type of extractant to recover lithium. In most of these studies, organophosphorus acids are used to separate the di- and trivalent metal ions from the mixture, as these have a significantly higher affinity for these extractant types. In these cases, lithium and other monovalent cations remain in the aqueous raffinate solution and are often obtained by subsequent precipitation or crystallization.

\subsubsection{Solvating Extractants}

Widely used and well-studied extractants of this class are neutral phosphorous compounds like TBP, TOP and TOPO.
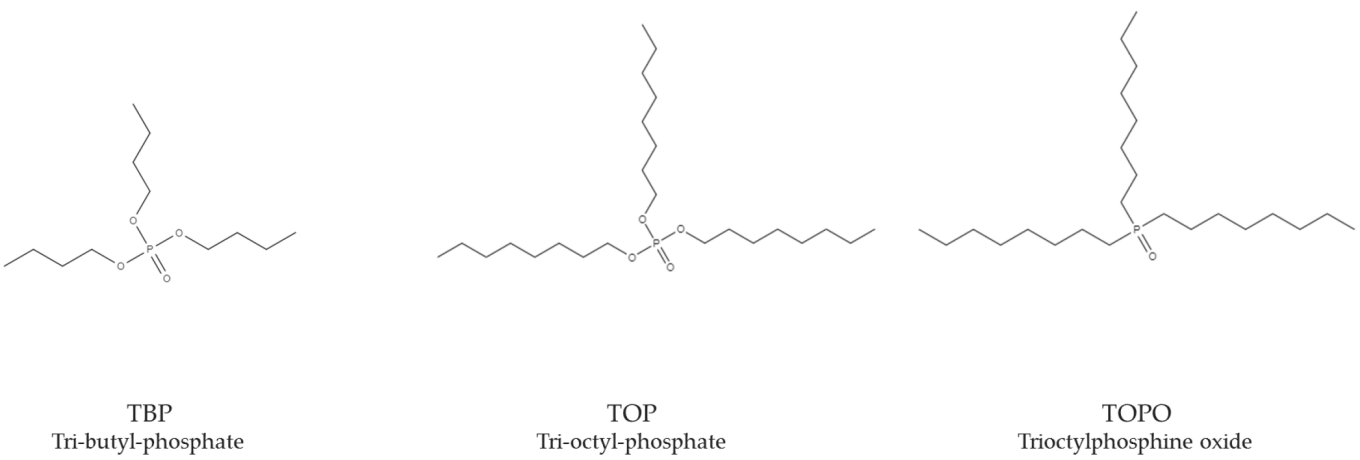

Figure 8: Most commonly used commercial solvating extractants.

The general extraction mechanism of solvating extractants is summarized in equation 3.6 (44). The metal ion $\mathrm{M}$ with the charge $\mathrm{n}$ is transferred into the organic phase with an inorganic ion $\mathrm{X}$, which serves for complexation, in combination with the solvating extractant B as a neutral salt.

$$
\mathrm{M}^{\mathrm{n}+}+\mathrm{nX}-\mathrm{b} \overline{\mathrm{B}} \rightleftharpoons \overline{\mathrm{MX}_{\mathrm{n}} \mathrm{B}_{\mathrm{b}}}
$$

The application of TBP in combination with coextractants like $\mathrm{FeCl}_{3}$ was investigated for the extraction of lithium from brines (45-47). The synergistic extraction of lithium by solvating extractants is often done by combining them with chelating extractants like $\beta$-diketones (48-55). Since this type of extraction is discussed very frequently in literature, synergistic extraction is discussed in more detail in the following section. 


\subsubsection{Synergistic Solvent Extraction}

Synergistic solvent extraction (SSX) is based on the motivation to significantly improve the extraction efficiency and/or selectivity of an extraction by combining two different extractant classes. In the area of lithium separation, this is usually attempted by combining a chelating extractant such as LIX51 or LIX54 with a neutral or solvating extractant $(56,57)$. However, it is also possible to separate the multivalent ions from lithium by extraction, usually by combining an acidic extractant such as P204 or Cyanex 272 again with a solvating extractant $(58,59)$. Due to the many possible combinations of different extractant types, there is a correspondingly large number of extraction mechanisms whose detailed description exceeds the scope of this review. A detailed discussion and presentation of the mechanisms related to metal ion extraction can be found at Attanassova et al. (60). More detailed representations of the extraction mechanism of solvating extractants in combination with $\beta$-diketone can be found in Swain et. al. (29). Chagnes et al. describe a synergistic effect, which is achieved by increasing the hydrophobicity of the actually active extractant by a second extractant which interacts with water molecules in the solvation shell of the active extractant and thus facilitates the transport of the metal ion into the organic phase (44). How much the extraction efficiency increases or decreases, in case of antagonistic effects, can be described by the factor SC, which is dependent on the distribution coefficients of the synergistic system $\mathrm{D}_{12}$, as well as those of the single systems $\mathrm{D}_{1}$ and $\mathrm{D}_{2}(44)$ :

$$
\mathrm{SC}=\frac{\log \mathrm{D}_{12}}{\left(\mathrm{D}_{1}+\mathrm{D}_{2}\right)}
$$

If there is synergy between the extractants used, SC becomes greater than unity. However, the extraction of the metal ion in the combined system may also worsen due to antagonistic effects. In this case SC becomes less than unity.

\subsubsection{Diluents}

Extractants are typically used only in diluted form in organic solvents, which are therefore typically called diluents. In addition to the costs, better rheological and coalescing properties and the fact that some extractants are solid at ambient temperature and therefor need to be dissolved, are decisive reasons for this (44). In addition to the synergistic effects that diluents can have on extraction, coalescence-based problems such as the appearance of crud or a third phase play an important role. The strength with which these phenomena appear can be strongly influenced by the choice of the diluent. Zhou et al. investigated the influence of three diluents on the extraction efficiency and third phase formation of lithium from an alkaline brine in three different diluents (46). They found that the extraction capacity of lithium with TBP decreased in the order MIBK (methyl isobutyl ketone) $>$ kerosene $>2$-octanol. The highest capacity of TBP/MIBK is attributed to a synergistic effect, since both TBP and MIBK are individually capable of extracting lithium, which is not the case for kerosene and 2-octanol due to the lack of suitable binding sites. While kerosene is an inert diluent and therefore neither improves nor worsens the extraction properties of TBP, in case of 2-octanol an antagonistic effect occurs due to weak hydrogen bridge interactions. Compared to the other two diluents, this leads to the worst extraction behavior. In contrast to the TBP/kerosene system, both MIBK and 2-octanol showed no formation of a third phase over the investigated concentration range of TBP. This highlights that for optimal process development ideal combinations of extractant and diluents have to be investigated.

\subsection{Process Routes}

As presented in Section 2, the usage of LLE in lithium production routes is limited to boron removal from brine concentrates and the extraction of transition metals in the field of LIB recycling. The following section presents examples of different process routes of different leaching feeds as wells as concentrated brine solution. 


\subsubsection{From Alkaline Brine Feed}

A study on the recovery of lithium from alkaline brine feed using a combination of a $\beta$-diketone and solvating extractants was published by Zhang et al. (61). Benzoyl-1,1,1-trifluotoaceton (HBTA) was used as chelating $\beta$-diketone. Since extraction of lithium by HBTA alone showed unsatisfactory extraction results, suitable solvating coextractants where investigated for synergistic extraction. A combination of HBTA $(0.4 \mathrm{~mol} / \mathrm{L})$ and TOPO $(0.3 \mathrm{~mol} / \mathrm{L})$ in kerosene as diluent were found to show the best extraction efficiency ( $95 \%$ extraction of lithium after three stages). Hydrochloric acid was used as scrubbing $(1 \mathrm{~mol} / \mathrm{L})$ and stripping $(3 \mathrm{~mol} / \mathrm{L})$ agent. The solvent is regenerated in an additional stage with sodium hydroxide $(2 \mathrm{~mol} / \mathrm{L})$ before reentering the extraction stage. After stripping the concentration of lithium was $15 \mathrm{~g} / \mathrm{L}$. The study was executed in a 7-stage mixer-settler battery (PTFE, 2 L settler volume) for 30 hours of stable operation. The flowsheet of the entire process is shown in Figure 9

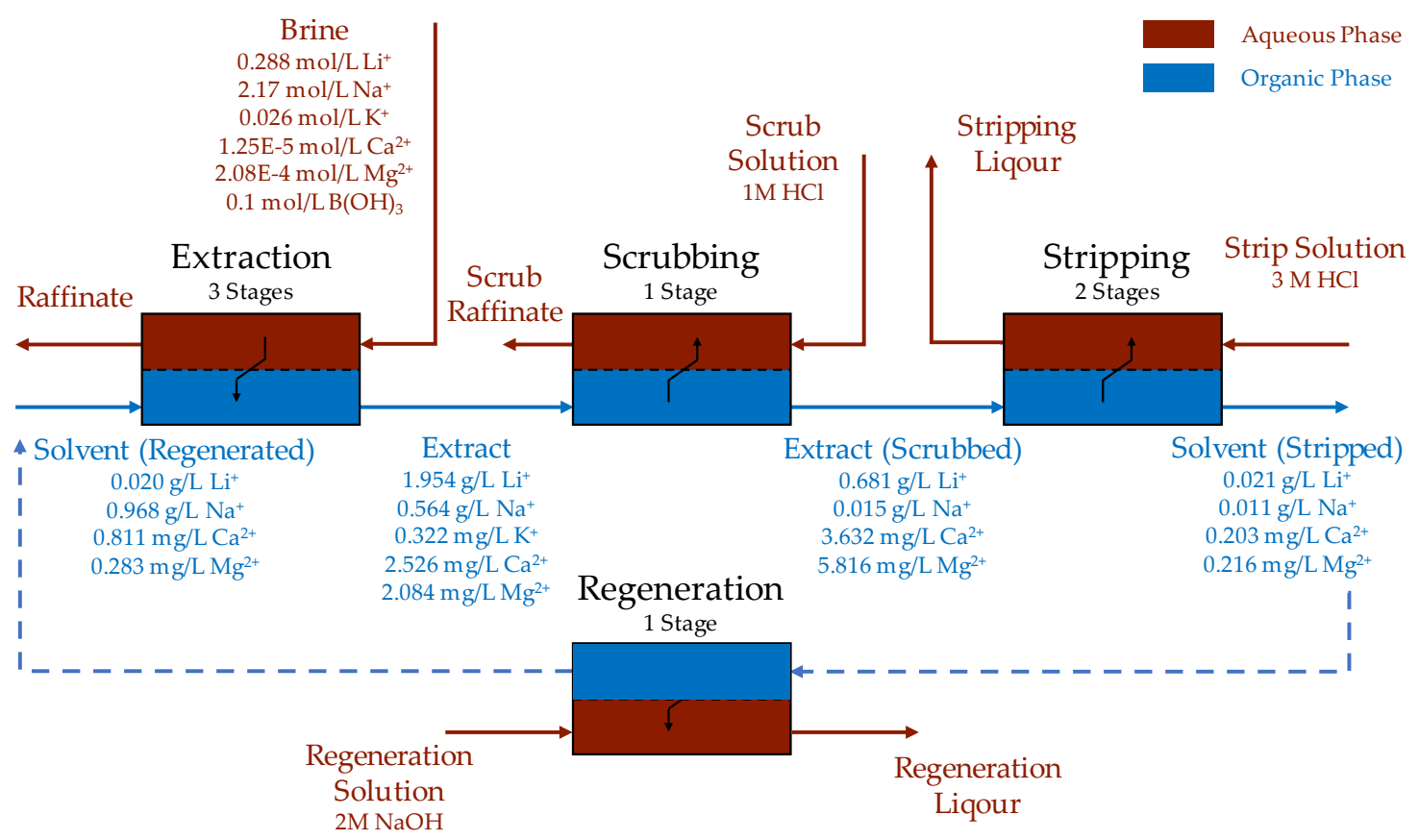

Figure 9: 7-stage counter-current extraction process (61).

\subsubsection{From Sulfuric Acid Feed}

Suzuki et al. have developed a process using Acorga M5640 to extract copper at a pH of $1.5-2.0$ from the sulfuric leach solution. The remaining metals such as aluminium, cobalt and lithium remain in the raffinate and are separated in further extraction stages. $\mathrm{P} 507$ ( $\mathrm{pH}$ 2.5-3.0) is used as an extractant to extract the trivalent aluminium from the solution in a second step. Finally, the aqueous raffinate phase contains the divalent cobalt and monovalent lithium, which are separated in the next extraction stage with a mixture of P507 and TOA at a pH between 5.5 and 6.0. Although Acorga M5640 has a higher selectivity for cobalt, the mixture of P507 and TOA later improves the stripping process. All extractions are performed with kerosene as diluent and a solvent ratio of 1:1. At a concentration of $10 \mathrm{vol} \% \mathrm{P} 507$ and $5 \mathrm{vol} \%$ TOA in the last extraction stage, a separation factor $\mathrm{Co} / \mathrm{Li}$ of over 1,000 is obtained (62). The complete process flowsheet is shown in Figure 10. 


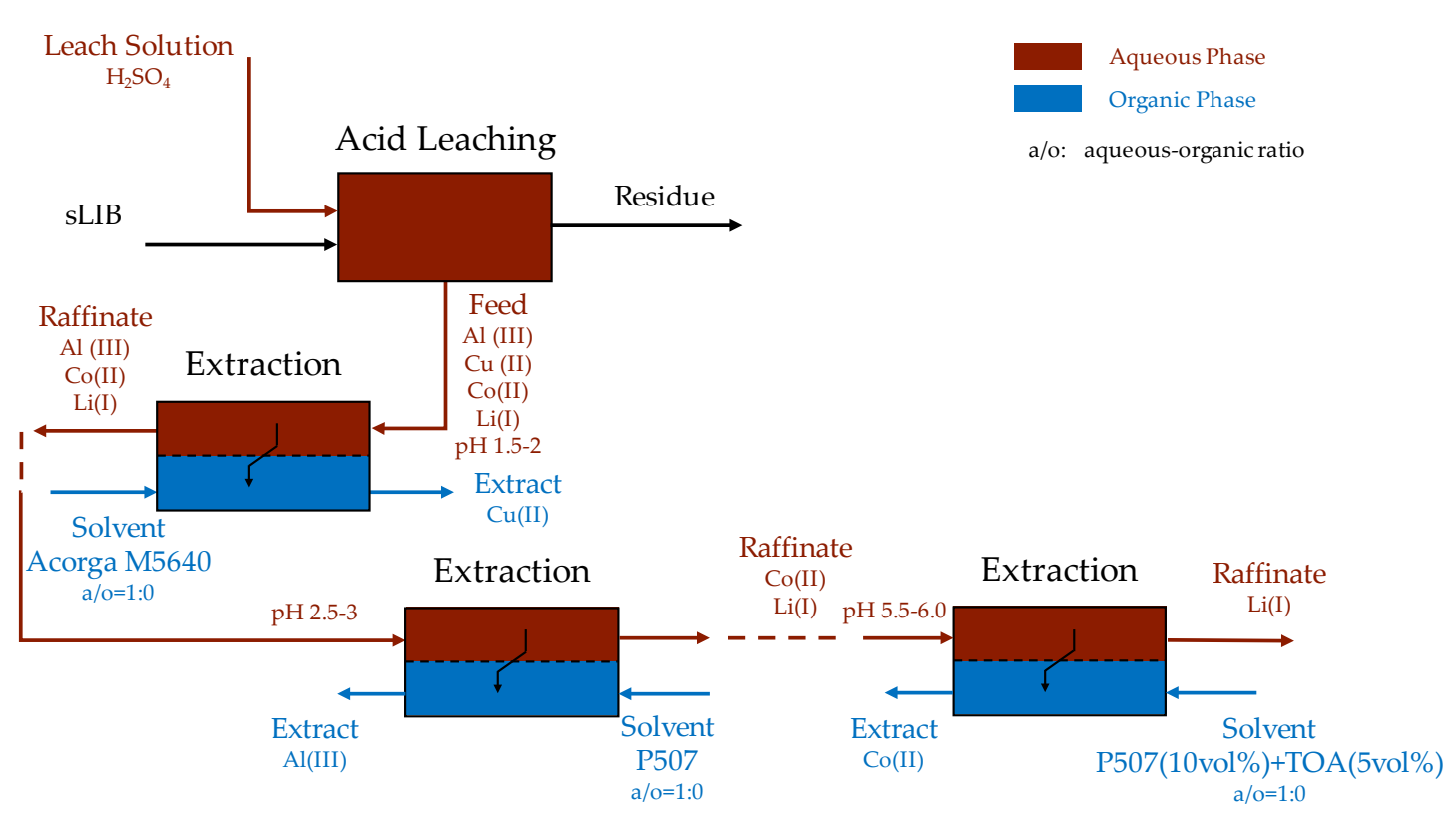

Figure 10: Proposed flowsheet for the recovery of metals from sulfuric acid feed (62).

\subsubsection{From Hydrochloric Acid Feed}

A study on the separation and recovery of lithium and other value metals from hydrochloric acid as feed was done by Zhang et al. (42).

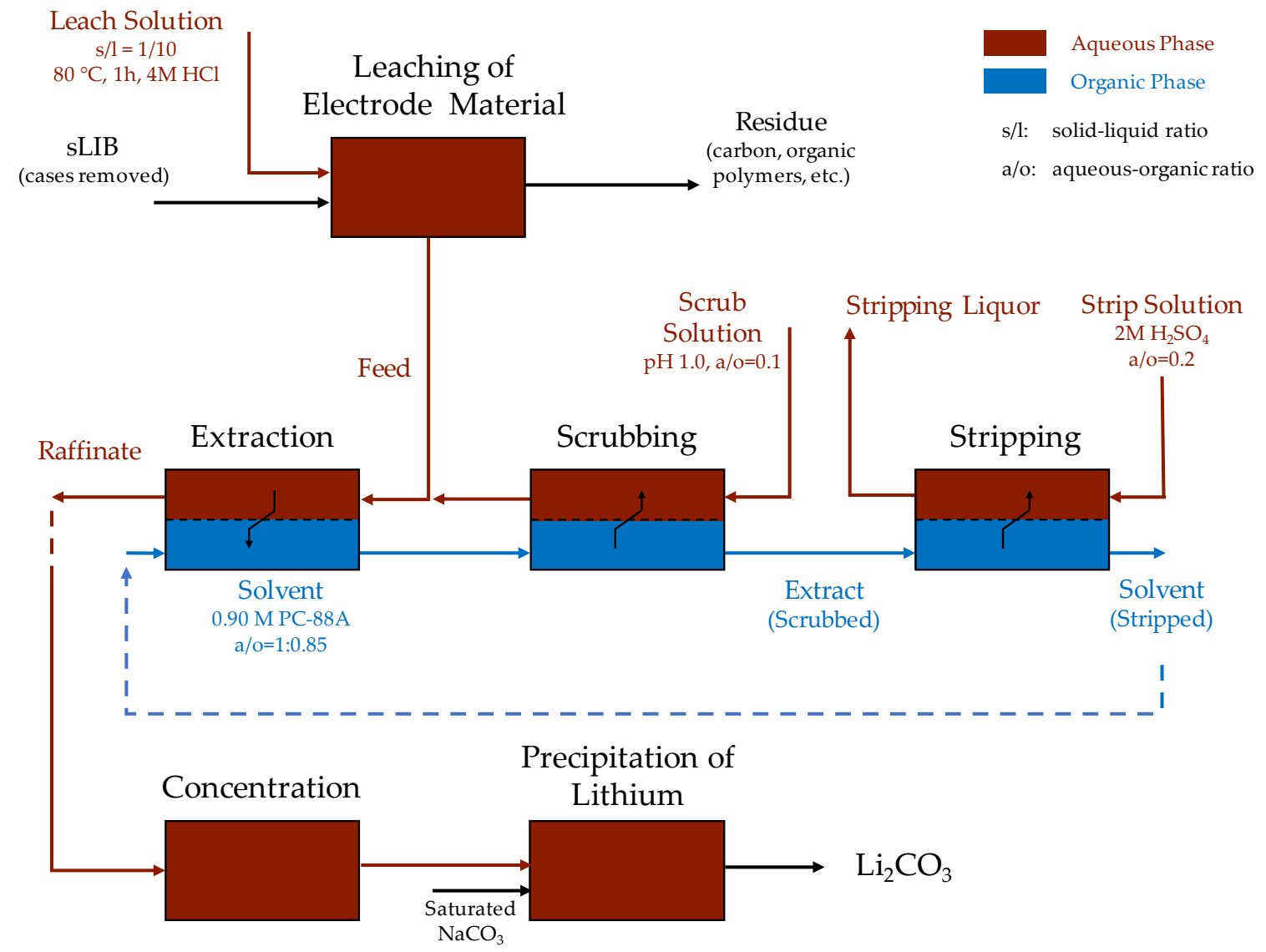

Figure 11: Hydrometallurgical recovery process for cobalt and lithium (42).

The flowsheet of process is shown in Figure 11. Leaching of disassambeld LIBs is done at $80{ }^{\circ} \mathrm{C}$ for a time of $1 \mathrm{~h}$ and a solid-liquid ratio of around 0.1 by $4 \mathrm{M} \mathrm{HCl}$. After leaching, the residues such as carbons and organic polymers are separated, and the leach liquor enters the extraction, stripping and 
scrubbing process. Extraction of cobalt is done with 0.9 M P507 diluted in kerosene. Coextracted lithium in the solvent phase is scrubbed with $\mathrm{CoCl}_{2} / \mathrm{HCl}$ solution and redirected into the extraction stage. The recovery of lithium is achieved by precipitation with saturated sodium carbonate after concentration of the aqueous raffinate stream. The precipitation is performed at $100{ }^{\circ} \mathrm{C}$ to lower the solubility of the resulting lithium carbonate in the aqueous solution. The final lithium product contains traces of cobalt below $0.07 \%$ and the overall recovery of lithium in the process reached $80 \%$.

\section{Chromatography}

\subsection{Chromatography Basics}

In chromatographic separation, two different phases are used. The first is the stationary phase, also called adsorbent. This phase is packed in a column and usually consists of spherical particles. The separation is based on the interaction between the substances and the stationary phase. The stationary phases can be influenced by adding different ligands to the particle surface. An example for a separation without ligands is the size exclusion chromatography (SEC, also known as gel permeation chromatography (GPC)). Here, the separation is only based on the molecular size. Another example is the ion exchange chromatography (IEX) where the separation is based on electrostatic interaction.

The second phase is the mobile phase, which is also called eluent. This phase can be liquid or gaseous and is pumped through the column. In this paper only liquid phases are considered. The adsorbed molecules/ions, which are also called adsorbate, can be eluted either isocratic (i.e. with the same eluent composition used in the loading step) or by changing the eluent. The eluent change can be carried out linearly or stepwise. A combination of both can also be carried out. After a separation is finished, the column has to be regenerated to elute all adsorbed compounds and is afterwards equilibrated to the starting conditions (63-65).

\subsection{Process Routes}

The separation of lithium from other alkali metal ions by chromatography is possible. An overview of different adsorption methods for the separation of lithium is shown in Table 2. Investigations were carried out with natural as well as synthetic brines. Utilizing inorganic acids, i.e. hydrochloric acid or nitric acid, is most common. A typical separation mechanism for the recovery of lithium is cation exchange. Strelow et al. have demonstrated that the usage of alcohols like ethanol or methanol has a positive influence on the selectivity between lithium and other ions (66). Based on this publication, Moriguti et al. designed a process to separate lithium from both mineral and aqueous samples (67). Moriguti et al. used a sulfonated cation exchanger (Muromac ${ }^{\circledR}$ AG 50W$\mathrm{X} 12$ ) with different ratios of $\mathrm{HCl}$ as the eluent. This process consists of four stages. First, major elements were removed with $2.8 \mathrm{M} \mathrm{HCl}$. In the second stage lithium and sodium were separated from other cations, using $0.15 \mathrm{M}$ hydrochloric acid. The separation of lithium from sodium was carried out using a solution of $0.5 \mathrm{M} \mathrm{HCl}(70 \%)$ and ethanol $(30 \%)$. In the fourth step, as final purification, $0.15 \mathrm{M} \mathrm{HCl}$ was used after a wash step with $\mathrm{H}_{2} \mathrm{O}$. The resin was regenerated by flushing the bed with 1.5 M HF. The experiments were performed on a polypropylene column. Abe et al. reported the adsorption of lithium on different cation exchangers. Elution was carried out under acidic conditions (using $\mathrm{HNO}_{3}$ ). In these studies the titanium(IV) antimonate cation exchanger shows good adsorption properties (68).

In addition to studies on strong cation exchangers with sulfonic groups, Oi et al. published investigations using weak cation exchangers with carboxyl groups (69). Bukowsky et al. reported the separation of lithium from calcium chloride and magnesium chloride using three different chelating cation exchangers and up to $1 \mathrm{M} \mathrm{HCl}$ as Eluent (70).

Recently, Chitrakar et al. investigated the adsorption of lithium on $\mathrm{H}_{2} \mathrm{TiO}_{3}$ ion exchanger. The adsorbed lithium was displaced with $\mathrm{H}^{+}$using $\mathrm{HCl}$ solution (71). Further Wang et al. reported the 
adsorption of lithium by iron-dropped $\mathrm{Li}_{2} \mathrm{TiO}_{3}$. The iron-dropped lithium was captured by a magnetic separation (72).

In addition to the ion exchange based separation, which is described above, some other mechanisms are mentioned in literature. Rona et al. have reported the separation of lithium by gel permeation chromatography. The experiments were carried out with distillated water (73). Lee et al. reported the separation of lithium from other alkali metal ions by reversed phase chromatography (74). After loading the feed in basic conditions, using $\mathrm{KOH}$ or $\mathrm{NH}_{4} \mathrm{OH}$, lithium was eluted using hydrochloric acid.

Ban et al. described the separation of lithium isotopes with a silica based monobenzo- 15 -crown-5 resin. The separation was carried out with a mixture of methanol (30\%) and $12 \mathrm{M} \mathrm{HCl}(70 \%)(75)$.

For the chromatogtraphic separation very harsh conditions like hydrofluoric acids or other inorganic acids with high concentrations are used. For the usage of chromatographic resins, long term stability test should be carried out.

Table 2: Overview of different adsorption methods for the separation of lithium.

\begin{tabular}{|c|c|c|c|c|c|c|}
\hline \multirow{2}{*}{ Resources } & \multicolumn{2}{|c|}{ Stationary Phase } & \multirow{2}{*}{ Eluent } & \multirow{2}{*}{$\begin{array}{l}\text { Feed concen- } \\
\text { tration }\end{array}$} & \multirow{2}{*}{$\begin{array}{l}\text { Yield } \\
{[\%]}\end{array}$} & \multirow{2}{*}{ Reference } \\
\hline & Ligand & Base material & & & & \\
\hline $\begin{array}{c}\mathrm{Li}^{+} \text {from rocks } \\
\mathrm{Li}^{+} \text {from } \\
\text { seawater }\end{array}$ & $\begin{array}{l}\text { Sulfonated cation } \\
\text { exchanger }\end{array}$ & $\begin{array}{c}\text { Polystyrene } \\
\text { divinylbenzene }\end{array}$ & $\begin{array}{c}\text { Ethanol }+ \\
\mathrm{HCl}\end{array}$ & $\begin{array}{c}8 \mathrm{ppm} \\
\text { Not given }\end{array}$ & $>99$ & (67) \\
\hline $\begin{array}{c}\mathrm{Li}^{+} \text {from } \\
\text { seawater } \\
\mathrm{Li}^{+} \text {from rocks }\end{array}$ & $\begin{array}{l}\text { Sulfonated cation } \\
\text { exchanger }\end{array}$ & $\begin{array}{c}\text { Polystyrene } \\
\text { divinylbenzene }\end{array}$ & $\mathrm{HCl}$ & $\begin{array}{l}<1 \mu \mathrm{g} / \mathrm{L} \\
<30 \mathrm{ppm}\end{array}$ & 98 & (76) \\
\hline $\begin{array}{l}\text { Different } \\
\text { cations }\end{array}$ & $\begin{array}{l}\text { Sulfonated cation } \\
\text { exchanger }\end{array}$ & $\begin{array}{c}\text { Polystyrene } \\
\text { divinylbenzene }\end{array}$ & $\begin{array}{l}\text { Inorganic } \\
\text { acids }\end{array}$ & $20 \mathrm{mmol} / \mathrm{L}$ & $\begin{array}{c}\text { not } \\
\text { given }\end{array}$ & (77) \\
\hline $\mathrm{Li}^{+}$from $\mathrm{Na}^{+}$ & $\begin{array}{l}\text { Sulfonated cation } \\
\text { exchanger }\end{array}$ & $\begin{array}{c}\text { Polystyrene } \\
\text { divinylbenzene }\end{array}$ & $\begin{array}{l}\text { Methanol } \\
+\mathrm{HCl}\end{array}$ & $0.1 \mathrm{~mol} / \mathrm{L}$ & 99 & (66) \\
\hline $\begin{array}{c}\mathrm{Li}^{+} \text {from } \mathrm{Na}^{+}, \\
\mathrm{Ca}^{2+}, \mathrm{Mg}^{2+}\end{array}$ & $\begin{array}{l}\text { Sulfonated cation } \\
\text { exchanger } \\
\text { Crystalline } \\
\text { Antimonic(V) } \\
\text { acid cation } \\
\text { exchanger }\end{array}$ & $\begin{array}{c}\text { Polystyrene } \\
\text { divinylbenzene }\end{array}$ & $\begin{array}{l}\text { Inorganic } \\
\text { acids }\end{array}$ & $\begin{array}{c}1 \mu \mathrm{mol} / \mathrm{L} \\
\text { (syntetic) } \\
7.9 \mu \mathrm{mol} / \mathrm{L} \\
\text { (rock) }\end{array}$ & $>99$ & (78) \\
\hline $\begin{array}{l}\mathrm{Li}^{+} \text {from alkali } \\
\text { metal ions }\end{array}$ & $\begin{array}{l}\text { Crystalline } \\
\text { Antimonic(V) } \\
\text { acid cation } \\
\text { exchanger }\end{array}$ & - & $\mathrm{HNO}_{3}$ & $1 \mathrm{mmol} / \mathrm{L}$ & $\begin{array}{l}\text { Not } \\
\text { given }\end{array}$ & (79) \\
\hline $\begin{array}{l}\mathrm{Li}^{+} \text {from alkali } \\
\text { metal ions }\end{array}$ & $\begin{array}{c}\text { Phospho- } \\
\text { antimonic(V) acid } \\
\text { cation exchanger }\end{array}$ & - & $\begin{array}{c}\mathrm{HNO}_{3} \\
\mathrm{NH}_{4} \mathrm{NO}_{3}\end{array}$ & $0.02 \mathrm{mmol} / \mathrm{L}$ & $\begin{array}{l}\text { Not } \\
\text { given }\end{array}$ & $(80)$ \\
\hline $\begin{array}{l}\mathrm{Li}^{+} \text {from alkali } \\
\text { metal ions }\end{array}$ & $\begin{array}{l}\text { Crystalline } \\
\text { Antimonic( }(\mathrm{V}) \\
\text { acid cation } \\
\text { exchanger }\end{array}$ & - & $\mathrm{HNO}_{3}$ & Not given & $\begin{array}{l}\text { Not } \\
\text { given }\end{array}$ & $(81)$ \\
\hline $\begin{array}{l}\mathrm{Li}^{+} \text {from } \\
\text { seawater }\end{array}$ & $\begin{array}{l}\text { tin(IV) antimonate } \\
\text { cation exchanger }\end{array}$ & - & $\mathrm{HNO}_{3}$ & $0.16 \mathrm{mg} / \mathrm{L}$ & 98 & (83) \\
\hline $\begin{array}{c}\mathrm{Li}^{+} \text {from } \\
\text { seawater } \\
\mathrm{Li}^{+} \text {from } \\
\text { hydrothermal } \\
\text { water }\end{array}$ & $\begin{array}{c}\text { titanium(IV) } \\
\text { antimonate cation } \\
\text { exchanger }\end{array}$ & - & $\mathrm{HNO}_{3}$ & $\begin{array}{c}0.17 \mathrm{mg} / \mathrm{L} \\
12.2 \mathrm{mg} / \mathrm{L} \\
1.8 \mathrm{mg} / \mathrm{L}\end{array}$ & $\begin{array}{l}98 \\
94\end{array}$ & $(68,82)$ \\
\hline
\end{tabular}




\begin{tabular}{|c|c|c|c|c|c|c|}
\hline \multirow{2}{*}{ Resources } & \multicolumn{2}{|c|}{ Stationary Phase } & \multirow{2}{*}{ Eluent } & \multirow{2}{*}{$\begin{array}{l}\text { Feed concen- } \\
\text { tration }\end{array}$} & \multirow{2}{*}{$\begin{array}{l}\text { Yield } \\
{[\%]}\end{array}$} & \multirow{2}{*}{ Reference } \\
\hline & Ligand & Base material & & & & \\
\hline $\mathrm{Li}^{+}$isotopes & $\begin{array}{l}\text { Sulfonated cation } \\
\text { exchanger }\end{array}$ & $\begin{array}{c}\text { Polystyrene } \\
\text { divinylbenzene }\end{array}$ & $\mathrm{HCl}$ & $0.5 \mu \mathrm{mol} / \mathrm{L}$ & 98 & (83) \\
\hline $\mathrm{Li}^{+}$isotopes & $\begin{array}{l}\text { Monobenzo-15- } \\
\text { crown-5 }\end{array}$ & Silica beads & $\begin{array}{l}\text { Methanol } \\
+\mathrm{HCl}\end{array}$ & $0.55 \mathrm{~mol} / \mathrm{L}$ & $\begin{array}{l}\text { Not } \\
\text { given }\end{array}$ & (75) \\
\hline $\mathrm{Li}^{+}$isotopes & Cryptand & $\begin{array}{c}\text { Polystyrene } \\
\text { divinylbenzene }\end{array}$ & Methanol & $0.12 \mathrm{~mol} / \mathrm{L}$ & $\begin{array}{l}\text { Not } \\
\text { given }\end{array}$ & (84) \\
\hline $\mathrm{Li}^{+}$isotopes & $\begin{array}{l}\text { Sulfonic cation } \\
\text { exchanger } \\
\text { Carboxyl cation } \\
\text { exchanger }\end{array}$ & $\begin{array}{l}\text { Crosslinked } \\
\text { polymer }\end{array}$ & $\begin{array}{c}\text { Displace- } \\
\text { ment with } \\
\mathrm{K}, \mathrm{Ca}, \mathrm{Sr}\end{array}$ & $0.1 \mathrm{~mol} / \mathrm{L}$ & $\begin{array}{l}\text { Not } \\
\text { given }\end{array}$ & (69) \\
\hline $\begin{array}{l}\mathrm{Li}^{+} \text {from dead } \\
\text { sea brines }\end{array}$ & $\begin{array}{l}\text { Gel permeation } \\
\text { chromatography }\end{array}$ & Polyacylamide & Water & $20 \mathrm{ppm}$ & $\begin{array}{l}\text { Not } \\
\text { given }\end{array}$ & (73) \\
\hline $\begin{array}{l}\mathrm{Li}^{+} \text {from alkali } \\
\text { metal ions }\end{array}$ & $\begin{array}{l}\text { Reversed phase } \\
\text { chromatography }\end{array}$ & $\begin{array}{l}\text { Polytetra- } \\
\text { fluoroethylene }\end{array}$ & $\begin{array}{c}\mathrm{KOH} / \mathrm{HCl} \\
\mathrm{NH}_{4} \mathrm{OH} / \mathrm{H} \\
\mathrm{Cl}\end{array}$ & Not given & $\begin{array}{l}\text { Not } \\
\text { given }\end{array}$ & (74) \\
\hline $\begin{array}{l}\mathrm{Li}^{+} \text {from } \mathrm{Ca}^{2+} \\
\text { and } \mathrm{Mg}^{2+}\end{array}$ & $\begin{array}{l}\text { Cation exchange } \\
\text { (chelating) }\end{array}$ & Polystyrol & $\mathrm{HCl}$ & $1 \mathrm{~mol} / \mathrm{L}$ & $\begin{array}{l}\text { Not } \\
\text { given }\end{array}$ & (70) \\
\hline Salt lake brine & $\begin{array}{l}\mathrm{H}_{2} \mathrm{TiO}_{3} \text { ion } \\
\text { exchanger }\end{array}$ & Not given & $\mathrm{HCl}$ & $1.6 \mathrm{~g} / \mathrm{L}$ & $>99$ & (71) \\
\hline $\mathrm{Li}^{+}$solution & $\begin{array}{c}\text { Fe dropped } \\
\mathrm{Li}_{2} \mathrm{TiO}_{3}\end{array}$ & Not given & $\mathrm{HCl}$ & $1.8 \mathrm{~g} / \mathrm{L}$ & 92 & (72) \\
\hline
\end{tabular}

\section{Conclusions and Further Perspectives}

The results of this review show that the recovery of lithium from LIB using LLE is currently limited to the extraction of multivalent metal ions. Direct extraction of lithium from the aqueous solutions using acidic extractants is extremely inefficient. Chelating extractants have the greatest potential for selectivity, which could be decisive for the currently insufficient purity of the lithium products obtained by many LIB recycling routes. At present, numerous research activities focus on the extraction of lithium from brines using a synergistic mixture of $\beta$-diketones and solvating extractants. First laboratory studies show the feasibility of extracting pure lithium, even in continuous operation over longer operating times. However, lithium concentration in the strip liquor is still relatively low. To increase the lithium concentration, the solvent ratio needs to be decreased. However, this leads to several more extraction stages because the extraction efficiency decreases. Chromatography could solve these late-stage downstream challenges efficiently, since purity and concentration can easily be increased in chromatography processes (85). Process times for concentration can be significantly decreased as well. However, most research is still in early development and operated on laboratory scale. Additionally, the strong acidic process conditions necessary for regeneration of the stationary phase with, e.g. hydrofluoric acid, can be critical for safe operation. In addition, many resins are designed for operation in far less acidic conditions, which decreases the lifetime of the stationary phase. Further development is necessary to develop less harsh conditions for elution and resins that are more robust.

Our review suggests that there is high potential for lithium separation using optimized LLE in combination with chromatography as hybrid separation processes to enable faster process times and better product quality. Hence, there is a need for more research dealing with hybrid separation processes for lithium recovery. Consistent methods for efficient process design and evaluation are available based on physical-chemical (rigorous) process modelling in combination with laboratory 
scale model parameter determination, which finally have to be validated in mini-plant operation $(86,87)$.

To enable industrial use of these technologies, feasibility of operation in pilot scale has to be carried out before industrialization. Therefore, such robust process development strategies have to be applied, that guide through the necessary steps starting from the first lab-scale studies up to the final stages of scale-up and process integration. Due to the environmental impact of the processes in large-scales, green process technologies should be followed strictly regarding the choice of media, recycling strategies, equipment design and advanced process control for optimal process operation incorporating modern sustainable production technology (88).

\section{References}

[1] U.S. Geological Survey. 2018. Mineral Commodtity Summaries 2018. https://minerals.usgs.gov/minerals/pubs/mcs/2018/mcs2018.pdf

[2] Elwert T, Römer F, Schneider K, Hua Q, Buchert M. 2018. Recycling of Batteries from Electric Vehicles. In Behaviour of Lithium-Ion Batteries in Electric Vehicles, ed. G Pistoia, B Liaw, pp. 289-321. Cham: Springer International Publishing

[3] Wiberg E, Wiberg N. 2007. Lehrbuch der anorganischen Chemie. Berlin, New York: W. de Gruyter. 102., stark umgearb. und verb. Aufl.

[4] Wietelmann U, Steinbild M. 2014. Lithium and Lithium Compounds. In Ullmann's Encyclopedia of Industrial Chemistry. Weinheim, Germany: Wiley-VCH Verlag GmbH \& Co. KGaA

[5] Elwert T, Goldmann D, Schirmer T, Strauß K. 2013. Recycling of lithium ion traction batteries. The LiBRI project. In EUMICON - Beiträge zu einer resilienten Rohstoffpolitik. EUMICON - contributions to a resilient raw materials policy, ed. L Weber, R Stiftner. Wien: Verein zur Förderung des Bergmannstages der Rohstoffinitiative sowie der Aus- und Weiterbildung auf dem Gebiet der Rohstoffe

[6] British Geological Survey. 2016. Mineral profile: Lithium

[7] Tran T, Luong VT. 2015. Lithium Production Processes. In Lithium process chemistry. Resources, extraction, batteries, and recycling, ed. A Chagnes, J Światowska, pp. 81-124. Amsterdam: Elsevier

[8] Elwert T, Goldmann D, Römer F, Buchert M, Merz C, Schueler D, Sutter J. 2016. Current Developments and Challenges in the Recycling of Key Components of (Hybrid) Electric Vehicles. Recycling 1 (3):25-60

[9] Elwert T, Goldmann D, Schirmer T, Strauß K. 2012. Phase composition of high lithium slags from the recycling of lithium ion batteries. World of Metallurgy - ERZMETALL 65 (3): $163-71$

[10] Quix M, van Horebeek D, Suetens T, WO2017/1216663A1

[11] Elwert T, Römer F, Schneider K, Hua Q, Buchert M. 2018. Recycling of Batteries from Electric Vehicles. In Behaviour of Lithium-Ion Batteries in Electric Vehicles, ed. G Pistoia, B Liaw. Cham: Springer International Publishing

[12] Franke MB, Nowotny N, Ndocko EN, Górak A, Strube J. 2008. Design and optimization of a hybrid distillation/melt crystallization process. AIChE J. 54 (11):2925-42

[13] Franke M, Górak A, Strube J. 2004. Auslegung und Optimierung von hybriden Trennverfahren. Chemie Ingenieur Technik 76 (3):199-210

[14] Ströhlein G, Schulte M, Strube J. 2003. Hybrid Processes: Design Method for Optimal Coupling of Chromatography and Crystallization Units. Separation Science and Technology 38 (14):3353-83

[15] Helling C, Strube J. 2013. Future Processing and Recycling Strategies for Rare Earths. Chemie Ingenieur Technik 85 (8):1272-81

[16] Free ML. 2013. Hydrometallurgy. Fundamentals and Applications. New York, NY: John Wiley \& Sons. 1., Auflage 
[17] Leistner J, Goerge A, Baecker W, Górak A, Strube J. 2002. Modelling methodology for the simulation of solvent extraction processes - cobalt/nickel. Proceedings of the International Solvent Extraction Conference, ISEC 2002:958-963

[18] Habashi F. 1970. Hydrometallurgy. New York, London: Gordon \& Breach

[19] Habashi F. 1969. Principles of extractive metallurgy. New York: Gordon and Breach

[20] Bart H-J. 2001. Reactive Extraction. Berlin, Heidelberg: Springer Berlin Heidelberg

[21] Schmidt A, Strube J. 2018. Application and Fundamentals of Liquid-Liquid Extraction Processes: Purification of Biologicals, Botanicals and Strategic Metals. In Press. Wiley

[22] Takahashi T, Habata Y, Iri Y. 1991. Extraction and transport of lithium ion by a crown ether-alkylphosphoric acid system [1]. Journal of Inclusion Phenomena and Molecular Recognition in Chemistry 11 (4):379-88

[23] Wang J, Kollman PA. 1998. Alkali Cation Extraction by 18-Crown-6 and Its Derivatives. A Free Energy Perturbation Study. J. Am. Chem. Soc. 120 (43):11106-14

[24] Czech BP, Babb DA, Son B, Bartsch RA. 1984. Functionalized 13-crown-4, 14-crown-4, 15-crown-4, and 16-crown-4 compounds. Synthesis and lithium ion complexation. J. Org. Chem. 49 (25):4805-10

[25] Bartsch RA, Goo M-J, Christian GD, Wen X, Czech BP, Chapoteau E, Kumar A. 1993. Influence of ring substituents and matrix on lithium / sodium selectivity of 14-crown-4 and benzo-13-crown-4-compounds. Analytica Chimica Acta 272 (2):285-92

[26] Kinard WF, Mcdowell WJ, Shoun RR. 2006. Studies of the Size-Selective Extraction of Alkali Metal Ions by the Synergistic Extraction System, Crown Ether-DI(2-Ethylhexyl) Phosphoric Acid-Benzene. Separation Science and Technology 15 (4):1013-24

[27] Yu H-R, Hu J-Q, Lu X-H, Ju X-J, Liu Z, et al. 2015. Insights into the effects of 2:1 "sandwich-type" crown-ether/metal-ion complexes in responsive host-guest systems. The journal of physical chemistry. B 119 (4):1696-705

[28] Torrejos REC, Nisola GM, Song HS, Han JW, Lawagon CP, et al. 2016. Liquid-liquid extraction of lithium using lipophilic dibenzo-14-crown-4 ether carboxylic acid in hydrophobic room temperature ionic liquid. Hydrometallurgy 164:362-71

[29] Swain B. 2016. Separation and purification of lithium by solvent extraction and supported liquid membrane, analysis of their mechanism. A review. J. Chem. Technol. Biotechnol. 91 (10):2549-62

[30] Strzelbicki J, Bartsch RA. 2002. Extraction of alkali metal cations from aqueous solutions by a crown ether carboxylic acid. Anal. Chem. 53 (12):1894-99

[31] Sadamatsu H, Morisada S, Kawakita H, Ohto K. 2014. Allosteric Coextraction of Sodium and Metal Ions with Calix[4]Arene Derivatives 3. Effect of Propyl Groups on SizeDiscrimination for the Second Coextracted Ion. Solvent Extraction and Ion Exchange 33 (3):264-77

[32] Sviben I, Galić N, Tomišić V, Frkanec L. 2015. Extraction and complexation of alkali and alkaline earth metal cations by lower-rim calix[4]arene diethylene glycol amide derivatives. New J. Chem. 39 (8):6099-107

[33] Ohto K. 2010. Review of the Extraction Behavior of Metal Cations with Calixarene Derivatives. SERDJ 17 (0):1-18

[34] Sadamatsu H, Hanada T, Morisada S, Kawakita H, Ohto K. 2016. Comprehensive comparison of alkali metal extraction with a series of calix[4]arene derivatives with propyl and/or acetic acid groups. J Incl Phenom Macrocycl Chem 84 (1-2):87-97

[35] Yoneyama T, Sadamatsu H, Kuwata S, Kawakita H, Ohto K. 2012. Allosteric coextraction of sodium and metal ions with calix4arene derivatives 2: first numerical evaluation for the allosteric effect on alkali metal extraction with crossed carboxylic acid type calix4arenes. Talanta 88:121-28

[36] Ohto K, Ishibashi H, Kawakita H, Inoue K, Oshima T. 2009. Allosteric coextraction of sodium and metal ions with calix[4]arene derivatives 1. J Incl Phenom Macrocycl Chem 65 (1-2):111-20 
[37] Hano T, Matsumoto M, Ohtake T, Egashir N, Hori F. 1992. RECOVERY OF LITHIUM FROM GEOTHERMAL WATER BY SOLVENT EXTRACTION TECHNIQUE. Solvent Extraction and Ion Exchange 10 (2):195-206

[38] Kang J, Senanayake G, Sohn J, Shin SM. 2010. Recovery of cobalt sulfate from spent lithium ion batteries by reductive leaching and solvent extraction with Cyanex 272 . Hydrometallurgy 100 (3-4):168-71

[39] Swain B, Jeong J, Lee J-c, Lee G-H. 2008. Development of process flow sheet for recovery of high pure cobalt from sulfate leach liquor of LIB industry waste: A mathematical model correlation to predict optimum operational conditions. Separation and Purification Technology 63 (2):360-69

[40] Swain B, Jeong J, Lee J-c, Lee G-H, Sohn J-S. 2007. Hydrometallurgical process for recovery of cobalt from waste cathodic active material generated during manufacturing of lithium ion batteries. Journal of Power Sources 167 (2):536-44

[41] Mantuano DP, Dorella G, Elias RCA, Mansur MB. 2006. Analysis of a hydrometallurgical route to recover base metals from spent rechargeable batteries by liquid-liquid extraction with Cyanex 272. Journal of Power Sources 159 (2):1510-18

[42] Zhang P, Yokoyama T, Itabashi O, Suzuki TM, Inoue K. 1998. Hydrometallurgical process for recovery of metal values from spent lithium-ion secondary batteries. Hydrometallurgy 47 (2):259-71

[43] Zhao JM, Shen XY, Deng FL, Wang FC, Wu Y, Liu HZ. 2011. Synergistic extraction and separation of valuable metals from waste cathodic material of lithium ion batteries using Cyanex 272 and PC-88A. Separation and Purification Technology 78 (3):345-51

[44] Chagnes A, Światowska J, eds. 2015. Lithium process chemistry. Resources, extraction, batteries, and recycling. Amsterdam: Elsevier

[45] Zhou Z, Qin W, Fei W, LI Y. 2012. A Study on Stoichiometry of Complexes of Tributyl Phosphate and Methyl Isobutyl Ketone with Lithium in the Presence of FeCl3. Chinese Journal of Chemical Engineering 20 (1):36-39

[46] Zhou Z, Qin W, Fei W. 2011. Extraction Equilibria of Lithium with Tributyl Phosphate in Three Diluents. J. Chem. Eng. Data 56 (9):3518-22

[47] Zhu SL, Piao XL, Gou ZM. 2000. Extraction of lithium from brine with neutral organophosphorous solvents. J. Tsinghua Univ.(Sci. Technol.) 40 (10):47-50

[48] Pranolo Y, Zhang W, Cheng CY. 2010. Recovery of metals from spent lithium-ion battery leach solutions with a mixed solvent extractant system. Hydrometallurgy 102 (1-4):37-42

[49] Ji L, Hu Y, Li L, Shi D, Li J, et al. 2016. Lithium Extraction with a Synergistic System of Dioctyl Phthalate and Tributyl Phosphate in Kerosene and FeCl3. Hydrometallurgy 162:7178

[50] Ji L, Li L, Shi D, Li J, Liu Z, Xu D, Song X. 2016. Extraction equilibria of lithium with N,N-bis(2-ethylhexyl)-3-oxobutanamide and tributyl phosphate in kerosene and $\mathrm{FeCl} 3$. Hydrometallurgy 164:304-12

[51] Chemical Equilibrium and Synergism for Solvent Extraction of Trace Lithium with Thenoyltrifluoroacetone in the Presence of Trioctylphosphine Oxide. 2003. Bulletin of the Korean Chemical Society 24 (10):1495-500

[52] Harvianto GR, Kim S-H, Ju C-S. 2016. Solvent extraction and stripping of lithium ion from aqueous solution and its application to seawater. Rare Met. 35 (12):948-53

[53] Healy TV. 1968. Synergism in the solvent extraction of alkali metal ions by thenoyl trifluoracetone. Journal of Inorganic and Nuclear Chemistry 30 (4):1025-36

[54] Kusakabe S, Sekine T. 1980. Studies on the Solvent Extraction of Metal Perchlorates. II. Extraction of Alkali Metal Perchlorates with Trioctylphosphine Oxide. BCSJ 53 (7):208788

[55] Kinugasa T, Nishibara H, Murao Y, Kawamura Y, Watanabe K, Takeuchi H. 1994. Equilibrium and Kinetics of Lithium Extraction by a Mixture of LIX54 and TOPO. J. Chem. Eng. Japan / JCEJ 27 (6):815-18 
[56] Pranolo Y, Zhu Z, Cheng CY. 2015. Separation of lithium from sodium in chloride solutions using SSX systems with LIX 54 and Cyanex 923. Hydrometallurgy 154:33-39

[57] Kunugita E, Kim JH, Komasawa I. 1989. Extraction and separation of lithium and sodium by solvent extraction with. BETA.-diketone and neutral ligand. KAGAKU KOGAKU RONBUNSHU 15 (3):504-10

[58] Swain B, Jeong J, Yoo K, Lee J-c. 2010. Synergistic separation of Co(II)/Li(I) for the recycling of LIB industry wastes by supported liquid membrane using Cyanex 272 and DR8R. Hydrometallurgy 101 (1-2):20-27

[59] Sharma AD, Patil ND, Patwardhan AW, Moorthy RK, Ghosh PK. 2016. Synergistic interplay between D2EHPA and TBP towards the extraction of lithium using hollow fiber supported liquid membrane. Separation Science and Technology 51 (13):2242-54

[60] Atanassova M, Kurteva V, Dukov I. 2016. The interaction of extractants during synergistic solvent extraction of metals. Is it an important reaction? RSC Adv. 6 (84):81250-65

[61] Zhang L, Li L, Shi D, Peng X, Song F, Nie F, Han W. 2018. Recovery of lithium from alkaline brine by solvent extraction with $\beta$-diketone. Hydrometallurgy 175:35-42

[62] Suzuki T, Nakamura T, Inoue Y, Niinae M, Shibata J. 2012. A hydrometallurgical process for the separation of aluminum, cobalt, copper and lithium in acidic sulfate media. Separation and Purification Technology 98:396-401

[63] Strube J, Schulte M, Arlt W. 2006. Fluidverfahrenstechnik. Grundlagen, Methodik, Technik, Praxis: Kapitel 5. Chromatographie. Weinheim: Wiley-VCH. 1st ed.

[64] Unger K. 1989. Handbuch der HPLC 1, 1. Darmstadt: GIT-Verl.

[65] Unger K. 1994. Handbuch der HPLC 2. Darmstadt: GIT-Verl.

[66] Strelow FWE, Weinert CHSW, van der Walt TN. 1974. Separation of lithium from sodium, beryllium and other elements by cation-exchange chromatography in nitric acid-methanol. Analytica Chimica Acta 71 (1):123-32

[67] Moriguti T, Nakamura E. 1998. High-yield lithium separation and the precise isotopic analysis for natural rock and aqueous samples. Chemical Geology 145 (1-2):91-104

[68] Abe M, Chitrakar R. 1987. Synthetic inorganic ion-exchange materials. XLV. Recovery of lithium from seawater and hydrothermal water by titanium (iv) antimonate cation exchanger. Hydrometallurgy 19 (1):117-28

[69] Oi T, Kawada K, Hosoe M, Kakihana H. 1991. Fractionation of Lithium Isotopes in CationExchange Chromatography. Separation Science and Technology 26 (10-11):1353-75

[70] Bukowsky H, Uhlemann E, Steinborn D. 1991. The recovery of pure lithium chloride from "brines" containing higher contents of calcium chloride and magnesium chloride. Hydrometallurgy 27 (3):317-25

[71] Chitrakar R, Makita Y, Ooi K, Sonoda A. 2014. Lithium recovery from salt lake brine by H2TiO3. Dalton transactions (Cambridge, England : 2003) 43 (23):8933-39

[72] Wang S, Zheng S, Wang Z, Cui W, Zhang H, et al. 2018. Superior lithium adsorption and required magnetic separation behavior of iron-doped lithium ion-sieves. Chemical Engineering Journal 332:160-68

[73] Rona M, Schmuckler G. 1973. Separation of lithium from dead sea brines by gel permeation chromatography. Talanta 20 (2):237-40

[74] Lee DA. 1967. Separation of lithium from other alkali metal ions by reversed phase chromatography. Journal of Chromatography A 26:342-45

[75] Ban Y, NOMURA M, FUJII Y. 2002. Chromatographic Separation of Lithium Isotopes with Silica Based Monobenzo-15-crown-5 Resin. Journal of Nuclear Science and Technology 39 (3):279-81

[76] You C-F, Chan L-H. 1996. Precise determination of lithium isotopic composition in low concentration natural samples. Geochimica et Cosmochimica Acta 60 (5):909-15

[77] Strelow FWE, Rethemeyer R, Bothma CJC. 1965. Ion Exchange Selectivity Scales for Cations in Nitric Acid and Sulfuric Acid Media with a Sulfonated Polystyrene Resin. Anal. Chem. 37 (1):106-11 
[78] Abe M, Ichsan EAA, Hayashi K. 2002. Ion-exchange separation of lithium from large amounts of sodium, calcium, and other elements by a double column of Dowex 50-X8 and crystalline antimonic(V) acid. Anal. Chem. 52 (3):524-27

[79] Abe M. 1969. Synthetic Inorganic Ion-exchange Materials. XIII. The Mutual Separation of Alkali Metals with Three Different Antimonic Acids. BCSJ 42 (9):2683-85

[80] Abe M. 1977. Synthetic inorganic ion-exchange materials. Journal of Chromatography $A$ 134 (2):507-12

[81] Abe M. 1979. Synthetic inorganic ion-exchange materials-XVIII. Journal of Inorganic and Nuclear Chemistry 41 (1):85-89

[82] Abe M, Hayashi K. 1984. Synthetic inorganic ion-exchange materials. XXXIV. Selective separation of lithium from seawater by tin(IV) antimonate cation exchanger. Hydrometallurgy 12 (1):83-93

[83] Chan LH. 1987. Lithium isotope analysis by thermal ionization mass spectrometry of lithium tetraborate. Anal. Chem. 59 (22):2662-65

[84] FUJINE S, SAITO K, SHIBA K. 1983. Lithium isotope separation by displacement chromatography using cryptand resin. J. Nucl. Sci. Technol. 20 (5):439-40

[85] Swain B. 2017. Recovery and recycling of lithium. A review. Separation and Purification Technology 172:388-403

[86] Sixt M, Strube J. 2018. Towards a Distinct and Quantitative Validation Method for Predictive Process Modelling - on the example of solid-liquid extraction processes of complex plant extracts. MDPI, Processes

[87] Strube, J, et al. 2012. Prädiktive Modellierung von Trennverfahren. Chemie Ingenieur Technik 84 (6)

[88] Both S, Strube J, Cravatto G. 2015. Mass Transfer Enhancement for Solid-Liquid Extractions. In Green Extraction of Natural Products, ed. F Chemat, J Strube, pp. 101-44. Weinheim, Germany: Wiley-VCH Verlag GmbH \& Co. KGaA 